\title{
Inducible Nitric Oxide Synthase in Rat Hepatic Lipocytes and the Effect of Nitric Oxide on Lipocyte Contractility
}

Don C. Rockey and John J. Chung

The Liver Center Laboratory, Department of Medicine, San Francisco General Hospital, and the University of California, San Francisco, California 94110

\begin{abstract}
In liver injury, perisinusoidal cells known as lipocytes (Ito cells) undergo "activation," acquiring smooth muscle-like features and a contractile phenotype. To assess whether contraction of these cells is regulated by nitric oxide (NO), we examined the production of NO by lipocytes and the effect of NO on lipocyte contractility. Cultured lipocytes were exposed to cytokines and/or LPS. Single agents had little or no effect on the level of inducible NO synthase (iNOS) mRNA.

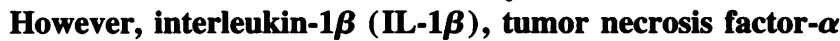
(TNF- $\alpha$ ), or LPS in combination with interferon- $\gamma$ (IFN$\gamma$ ) stimulated iNOS mRNA, which was present within $4 \mathrm{~h}$ after exposure. iNOS mRNA levels were paralleled by changes in nitrite (a metabolic product of NO). Intraperitoneal administration of IFN- $\gamma$, TNF- $\alpha$, and LPS led to rapid induction of iNOS mRNA in lipocytes, confirming in vivo the culture findings. Ligation of the common hepatic bile duct, which induces periportal-based liver injury, stimulated iNOS mRNA in lipocytes. Transforming growth factor- $\beta 1$ decreased IFN- $\gamma /$ TNF- $\alpha$-stimulated iNOS mRNA and nitrite. Finally, the effect of NO on lipocyte contractility was examined. In cells incubated with IFN- $\gamma$ and TNF- $\alpha$, the contractile response to either serum or endothelin-1 was blocked. Contraction was restored entirely by an inhibitor of $\mathrm{NO}$ synthase, $\mathbf{N}^{\mathbf{G}}$-monomethylarginine. Furthermore, 8bromoguanosine $3^{\prime}: 5$ '-cyclic monophosphate and sodium nitroprusside inhibited lipocyte contractility, consistent with the effect of NO induced by cytokines. We conclude that NO is a potent modulator of lipocyte contractility and may regulate this function by autocrine (or intracrine) mechanisms. Moreover, NO may play an important role in liver injury, countering the effect of contractile agonists on lipocytes. (J. Clin. Invest. 1995. 95:1199-1206.) Key words: liver - myofibroblast • endothelin • Ito cell • sinusoid

\section{Introduction}

Nitric oxide (NO) ${ }^{1}$ is produced from L-arginine by a variety of cells, including vascular endothelial cells $(1,2)$, macrophages

Address correspondence to Don C. Rockey, Liver Center Laboratory, Building 40, Room 4102, San Francisco General Hospital, San Francisco, CA 94110.

Received for publication 22 June 1994 and in revised form 20 October 1994.

1. Abbreviations used in this paper: BrcGMP, 8-bromoguanosine $3^{\prime}: 5^{\prime}-$ cyclic monophosphate; cGMP, guanosine $3^{\prime}: 5^{\prime}$-cyclic monophosphate; NMMA, $\mathrm{N}^{\mathrm{G}}$-monomethylarginine; $\mathrm{NO}$, nitric oxide.

J. Clin. Invest.

(c) The American Society for Clinical Investigation, Inc.

0021-9738/95/03/1199/08 $\$ 2.00$

Volume 95, March 1995, 1199-1206
(3-5), Kupffer cells (6), neurons (7), smooth muscle cells (8), cardiac myocytes (9), and hepatocytes (10). It is generated from L-arginine by NO synthases, which exist in constitutive and inducible isoforms. Two apparently distinct cDNAs for the constitutive form have been isolated, one from vascular endothelial cells (11-13) and the other from neurons (14). Inducible isoforms have been cloned from a variety of cell types, including macrophages $(3,4)$, smooth muscle cells $(15)$, chondrocytes $(16)$, and hepatocytes $(17,18)$.

The roles attributed to NO include neurotransmission, host defense via antimicrobial activity, and relaxation of vascular smooth muscle $(19,20)$. In liver, NO is generated after administration of endotoxin $(5,21,22)$ in both parenchymal and nonparenchymal cells, suggesting a possible role in host defense. The smooth muscle-relaxing properties of NO may be important, affecting sinusoidal hemodynamics, but have been examined little. In theory, NO could oppose vasoconstrictors such as endothelin-1, which stimulate contraction of liver smooth muscle cells or sinusoidal contractile elements (23).

Recent data indicate that perisinusoidal rat hepatic lipocytes (Ito, fat-storing cells) exhibit smooth muscle characteristics, including expression of desmin and endothelin receptors (24). After their "activation" in liver injury, they are contractile (25) and thus have been viewed as potential regulators of sinusoidal blood flow in the liver. Recent studies suggest that contraction may be elicited endogenously by endothelin-1 released (24) by lipocytes themselves. The prolonged effect of endothelin-1 on lipocyte contraction (25) is at odds with dynamic modulation of sinusoidal blood flow in vivo, suggesting that counter-regulators are present. We postulated that NO is a likely candidate.

NO is generated by hepatocytes $(17)$, Kupffer cells $(5,26)$, and endothelial cells $(21,26)$ and could exert paracrine effects on lipocytes; the calculated diffusion distances are realistic, the reactivity of NO notwithstanding (27). However, if present, an autocrine mechanism could play a predominant role. Therefore, the aim of this study was to determine (1) whether cultured lipocytes synthesized NO synthase(s) and produced NO, (2) whether NO synthase was induced by lipocytes in vivo, and (3) whether NO opposed the effects of known contractile agonists.

\section{Methods}

Cell isolation and culture. Lipocytes were isolated from retired male breeder Sprague-Dawley rats $(450-550 \mathrm{~g})$ as described $(28,29)$. In brief, after in situ perfusion of the liver with $0.25 \mathrm{mg}$ percent pronase and $0.013 \mathrm{mg}$ percent collagenase (both from Boehringer Mannheim, Indianapolis, IN), the dispersed cells were fractionated on a discontinuous Nycodenz (Accurate Chemical \& Scientific Co., Westbury, NY) density gradient. After isolation, lipocytes were suspended in modified medium 199 (30) containing 20\% serum ( $10 \%$ horse/10\% calf) (Flow Laboratories, Inc., Naperville, IL). Modified medium 199 contains $0.022 \mathrm{mM}$ L-arginine. Lipocytes were $\geq 99 \%$ pure as assessed by a combination of phase-contrast microscopy and desmin immunoreactiv- 
ity and by demonstration of characteristic cellular vitamin A autofluorescence (28). For standard lipocyte culture, cells were plated at a density of $5.0 \times 10^{5}$ cells per ml. Plating efficiency, routinely determined by direct cell counting, was 50-75\%. All cells were maintained in a humidified $2 \% \mathrm{CO}_{2}$ incubator at $37^{\circ} \mathrm{C}$. Medium was changed $24 \mathrm{~h}$ after plating and every $48 \mathrm{~h}$ thereafter.

Interferon- $\gamma$, tumor necrosis factor- $\alpha$, interleukin- $1 \beta$, lipopolysaccharide, and transforming growth factor $\beta-1$. Rat interferon- $\gamma$ (IFN- $\gamma$; Gibco BRL, Gaithersburg, MD), mouse tumor necrosis factor- $\alpha$ (TNF$\alpha$; Sigma Chemical Co., St. Louis, MO), mouse interleukin-1 $\beta$ (IL-1 $\beta$; R \& D Systems, Minneapolis, MN), and human transforming growth factor- $\beta 1$ (TGF- $\beta 1$; R \& D Systems) (all in recombinant form) were stored at $-70^{\circ} \mathrm{C}$ in PBS containing $2 \%$ BSA. Lipopolysaccharide (LPS; Salmonella typhimurium; Sigma Chemical Co.) was diluted in PBS and stored at $4^{\circ} \mathrm{C}$.

Inducible NO synthase cDNA isolation. Homology PCR was used to isolate a 600-bp sequence of an inducible NO synthase mRNA. Briefly, total RNA from lipocytes exposed to IFN- $\gamma$ and TNF- $\alpha$ (see following section) was isolated, and first-strand cDNA was synthesized by reverse transcription with an oligo(dT) primer according to the manufacturer's protocol (Gibco BRL). For amplification of a specific NO synthase, PCR was performed with the following primers corresponding to the known sequence of the rat vascular smooth muscle inducible NO synthase (15): forward, TTGTGTCAGCCCTCCAGAGTAC (amino acids 858-864 of vascular smooth muscle inducible NO synthase); reverse, CTGCAGGATGTCTTGAACGTA (amino acids 1052-1058). Denaturation, annealing, and elongation were at 94, 55, and $72^{\circ} \mathrm{C}$ for 1,1 , and $1 \mathrm{~min}$, respectively, for 25 cycles. PCR products were electrophoresed on an $0.8 \%$ agarose gel, extracted, and cloned into the EcoRI and HindIII sites of PGEM-3 (Promega, Madison, WI). The cloned fragment was sequenced directly with a DNA sequencer (model 373A, Applied Biosystems) and Dye Deoxy Terminator kit (Applied Biosystems, Foster City, CA).

A cDNA coding for mouse macrophage inducible NO synthase was provided by Dr. Cunningham (Boston, MA) (4), and a 307-bp fragment was subcloned into PGEM-4 (Promega) for use in RNase protection assays.

RNA isolation and mRNA detection. Total RNA was extracted in guanidinium isothiocyanate by the method of Chomczynski and Sacchi (31). The concentration of RNA was determined spectrophotometrically, and the integrity of all samples was documented by visualization of $18 \mathrm{~S}$ and $28 \mathrm{~S}$ ribosomal bands after electrophoresis through an $0.8 \%$ formaldehyde/agarose minigel stained with ethidium bromide.

Radiolabeled cRNA was generated by transcription with SP6 or T7 polymerase using $\left[\alpha-{ }^{32} \mathrm{P}\right] \mathrm{CTP}(32)$. Specific activity of all radiolabeled transcripts was $\sim 0.5 \times 10^{9} \mathrm{cpm} / \mu \mathrm{g}$.

Total RNA was incubated with $0.5 \times 10^{6}$ to $1.0 \times 10^{6}$ Cerenkov cpm of ${ }^{32} \mathrm{P}$-labeled cRNA, denatured at $78^{\circ} \mathrm{C}$, and hybridized in solution for $16 \mathrm{~h}$ at a temperature established as optimal in preliminary experiments (range $55-65^{\circ} \mathrm{C}$ ). After hybridization, T2 RNase (Gibco BRL) was added to digest unbound label and unprotected mRNA. For some experiments, RNase A and T1, prepared as previously described (33), were substituted for T2 RNase. The protected hybrids were denatured and separated by electrophoresis through a $5 \%$ polyacrylamide/urea sequencing gel. Dried gels were applied to x-ray film (X-Omat AR-5, Eastman Kodak Co., Rochester, NY) for 12-24 h. Bands corresponding to the protected labeled fragment were quantitated by scanning densitometry (Hoefer Scientific Instruments, San Francisco, CA).

Nitrite assay. After incubation of cells with IFN- $\gamma$, TNF- $\alpha$, IL-1 $\beta$, and LPS, alone or in combination, aliquots of culture medium supernatants were removed and immediately assayed for nitrite, as a measure of NO (34). Equal volumes of medium and Greiss reagent ( 1 part $1 \%$ sulfanilamide in $5 \%$ phosphoric acid and $0.1 \%$ napthylethylenediamine dihydrochloride in distilled water) were mixed at room temperature. The absorbance of the reaction product was measured at $546 \mathrm{~nm}$. The values obtained were compared with a standard curve established by adding known quantities of sodium nitrite to the medium used for cell culture and normalized to cell number as determined by cell counting or by DNA assay. The latter was measured fluorometrically (35).

Collagen lattice preparation. Contraction of lipocytes on collagen lattices was performed in 24-well flat-bottom tissue culture plates (Corning Glass Works, Corning, NY) as previously described (25). Briefly, culture vessels were preincubated with PBS (Sigma Chemical Co.) containing $1 \%$ BSA (Sigma Chemical Co.) for at least $1 \mathrm{~h}$ at $37^{\circ} \mathrm{C}$, washed twice with PBS, and air dried. A combination of 8 parts Vitrogen (Celltrix Corp., Santa Clara, CA), 1 part 10× MEM (Gibco BRL, Grand Island, NY), and 1 part $0.2 \mathrm{M}$ Hepes (resulting in a final collagen concentration of $2.4 \mathrm{mg} / \mathrm{ml}$ ) were mixed at $4^{\circ} \mathrm{C}$. The solution was added to the culture vessel and incubated for $1 \mathrm{~h}$ at $37^{\circ} \mathrm{C}$ to allow gelation. Lipocytes suspended in culture medium were layered on top of formed collagen lattices at a density of $2.5 \times 10^{5}$ cells per ml of culture media. After a specified time period, lattices were detached by gentle circumferential dislodgement using a micropipette tip. The change in lattice diameter was monitored, and results were expressed as the change in area over time.

Model of liver injury. To induce liver injury, the common bile duct was ligated and sectioned (36). Sham-operated controls consisted of animals that underwent laparotomy and subsequent palpation of the common bile duct. Lipocytes were isolated from these animals in the same manner as previously described.

Statistics. The Student's paired $t$ test was used for statistical comparisons. Each experiment used cells from a different animal. In the calculation of mean values and statistical variation, $n$ refers to the number of separate experiments each with an individual cell preparation. Error bars depict the SEM; absence of error bars indicates that the SEM was $<1 \%$, unless stated otherwise.

\section{Results}

Characterization of inducible NO synthase in lipocytes. The cDNA isolated by PCR of lipocyte RNA extracts was identical at the nucleotide level to the previously described rat vascular smooth muscle cDNA (15). The 600-bp fragment was 95.2 and $99 \%$ identical at the nucleotide and predicted amino acid sequence levels, respectively, to the murine macrophage cDNA previously described (5).

Inducible NO synthase mRNA and NO in cultured lipocytes. Our initial approach was to establish that NO synthase and NO were inducible in lipocytes. In early experiments, IFN- $\gamma$, IL$1 \beta$, and TNF- $\alpha$, alone or in combination, were added to cultured lipocytes that had been maintained in primary culture for $4 \mathrm{~d}$, and inducible NO synthase mRNA was quantified by RNase protection assay using the cloned 600 -bp fragment previously described (Fig. 1). The level of NO synthase mRNA was greatest in cells exposed to a combination of IFN- $\gamma$ and TNF- $\alpha$. In general, it predicted nitrite levels measured under the same conditions (see following discussion). Inducible NO synthase mRNA was abundant also after IFN- $\gamma$ plus IL- $1 \beta$, but was not detectable in control cells (no exposure to cytokines) or in those exposed to IL- $1 \beta$ or TNF- $\alpha$ alone. Small amounts of inducible NO synthase mRNA were detectable after IFN- $\gamma$ alone. Addition of IL- $1 \beta$ to TNF- $\alpha$ and IFN- $\gamma$ did not result in significant further stimulation of inducible NO synthase mRNA over that for IFN- $\gamma$ and TNF- $\alpha$ (data not shown).

Production of NO was confirmed by measurement of nitrite in lipocyte culture supernatants after exposure to cytokines alone or in combination (Fig. 2). Single agents had no significant effect on NO production, but IFN- $\gamma$ with either TNF- $\alpha$ or IL- $1 \beta$ markedly stimulated NO. Whereas IFN $-\gamma$ alone induced small amounts of NO synthase mRNA, this agent alone did not result in significant elevation of nitrite levels. 


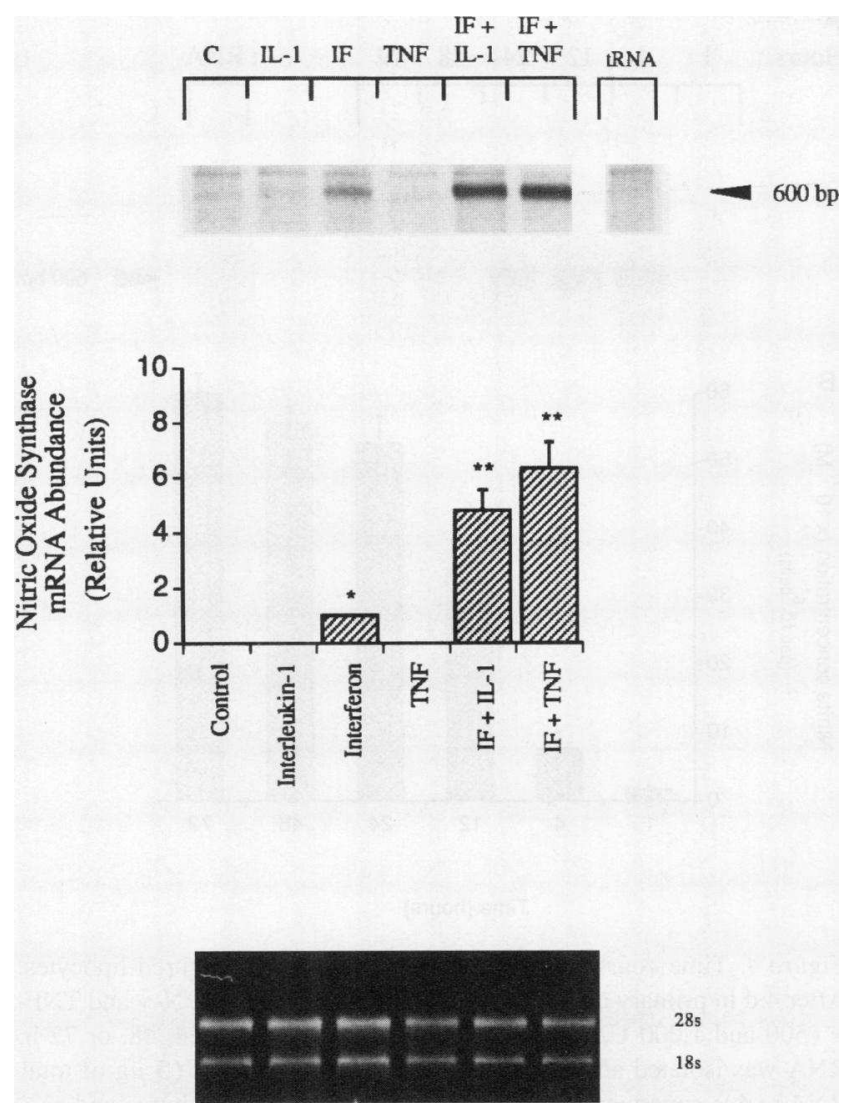

Figure 1. Inducible NO synthase mRNA in cultured lipocytes. Lipocytes were isolated and placed in primary culture as described in Methods. At day 4 in culture, IFN- $\gamma(500 \mathrm{U} / \mathrm{ml})$ TNF- $\alpha(1,000 \mathrm{U} / \mathrm{ml}), \mathrm{IL}-1 \beta$ $(50 \mathrm{pg} / \mathrm{ml})$, alone or in combination, were added to standard medium alone. Total cellular RNA was isolated $24 \mathrm{~h}$ after exposure to cytokines. RNase protection assay was performed with $5 \mu \mathrm{g}$ of total RNA. Inducible NO synthase mRNA was identified at the expected size (top). tRNA ( $5 \mu \mathrm{g})$ was used as a negative control sample. By scanning densitometry, NO synthase mRNA abundance was normalized to arbitrary units by assigning the value of 1 to NO synthase mRNA abundance with IFN- $\gamma$ alone (middle; $n=3 ; *, * * P<0.001$ for differences between IF $\gamma$ and IL-1 TNF, and between cytokines alone and IFN- $\gamma$ / IL- $\beta$ or IFN- $\gamma /$ TNF- $\alpha$, respectively). The integrity of RNA was documented after electrophoresis through an $\mathbf{0 . 8 \%}$ formaldehyde/agarose minigel (bottom; $1 \mu \mathrm{g}$ of total RNA is shown). Control refers to cultures without IFN- $\gamma$, TNF- $\alpha$, or IL- $1 \beta$. Abbreviations used: IF, interferon- $\gamma$; TNF, tumor necrosis factor- $\alpha$; IL-1, interleukin- $1 \beta$.

Cirrhotic patients have been reported to have elevated plasma endotoxin levels, implying a role of NO in the hemodynamic alterations in cirrhosis (37). To investigate the possibility that endotoxin may modulate NO in lipocytes in such a setting, we examined the effect of LPS on inducible NO synthase mRNA and nitrite (Fig. 3, $A$ and $B$ ). LPS alone or in combination with IL$1 \beta$ or TNF- $\alpha$ had no effect on NO synthase mRNA or nitrite. However, LPS plus IFN- $\gamma$ resulted in stimulation of inducible NO synthase mRNA and production of nitrite. LPS/IFN- $\gamma$ with or without TNF- $\alpha$ caused a significant increase in inducible NO synthase mRNA and nitrite relative to that with IFN- $\gamma /$ TNF- $\alpha$. Thus LPS appears to be a potent adjunct inducer of NO synthase when combined with IFN- $\gamma$ (alone or with TNF- $\alpha$ ).

The time course of NO synthase mRNA and NO production by IFN- $\gamma$ and TNF- $\alpha$ was examined (Fig. $4, A$ and $B$ ). In the

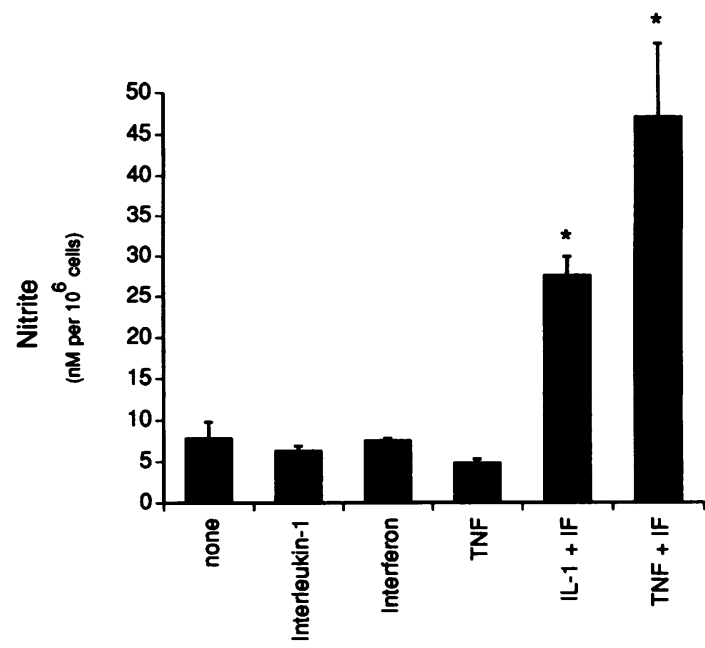

Cytokine(s)

Figure 2. Nitrite production in cultured lipocytes. Lipocytes were isolated, cultured, and exposed to IFN- $\gamma$, TNF- $\alpha$, and IL- $1 \beta$, alone or in combination, as in Fig. 1. After incubation of cells with IFN- $\gamma$ ( 500 $\mathrm{U} / \mathrm{ml}) ; \mathrm{TNF}-\alpha(1,000 \mathrm{U} / \mathrm{ml})$, and IL- $1 \beta(50 \mathrm{pg} / \mathrm{ml})$ for $24 \mathrm{~h}$, medium was removed for nitrite analysis as described in Methods. Nitrite concentration is expressed relative to the number of cells in culture $(n=3$; ${ }^{*} P<0.01$ for differences between cytokines alone and IFN- $\gamma / \mathrm{IL}-1 \beta$ or IFN- $\gamma /$ TNF- $\alpha$ ). Abbreviations used: IF, interferon- $\gamma$; TNF, tumor necrosis factor- $\alpha$; IL-1, interleukin- $1 \beta$.

presence of IFN- $\gamma$ and TNF- $\alpha$, NO synthase mRNA was not detectable after $1 \mathrm{~h}$, but was abundant by $4 \mathrm{~h}$, remained elevated for $24 \mathrm{~h}$, and declined thereafter (Fig. $4 \mathrm{~A}$ ). Nitrite levels rose more slowly and appeared to remain stable after $24 \mathrm{~h}$ (Fig. 4 $B)$. The rate of nitrite accumulation dropped substantially after $24 \mathrm{~h}$ in the continued presence of IFN- $\gamma$ and TNF- $\alpha$.

Over the first $7 \mathrm{~d}$ in primary culture, lipocytes undergo a well-characterized process termed activation, which is associated with loss of retinoid stores, cellular proliferation, and upregulation of TGF- $\beta$, platelet-derived growth factor $\beta$ receptor, and smooth muscle $\alpha$-actin (38). To determine whether NO induction was influenced by the activation state of lipocytes, we examined NO synthesis at different time points during activation. NO production appeared to be equally stimulable both in early culture and in late culture. Nitrite levels after IFN- $\gamma$ and TNF- $\alpha$ exposure were similar after 1, 3, and $6 \mathrm{~d}$ in primary culture (Fig. 5). Because lipocyte activation is associated with proliferation, DNA content of cultures was assayed, and the data were expressed relative to this internal control.

Regulation of NO synthase mRNA in vivo. The culture studies suggested that NO synthase mRNA can be dynamically modulated and imply that this may be an important mechanism by which NO is regulated in vivo. After intraperitoneal injection of IFN- $\gamma$, TNF- $\alpha$, and LPS, fresh lipocyte isolates were prepared and analyzed. Similar to the situation in culture, inducible NO synthase mRNA in vivo increased rapidly (within $4 \mathrm{~h}$ ) after a single exposure to IFN- $\gamma$, TNF- $\alpha$, and LPS (Fig. 6) and then declined. In contrast to culture, however, inducible NO synthase mRNA was not evident $24 \mathrm{~h}$ after exposure to cytokines and LPS.

Induction of NO synthase was examined also in a model of liver injury. After bile duct ligation, an increase in specific NO 
A

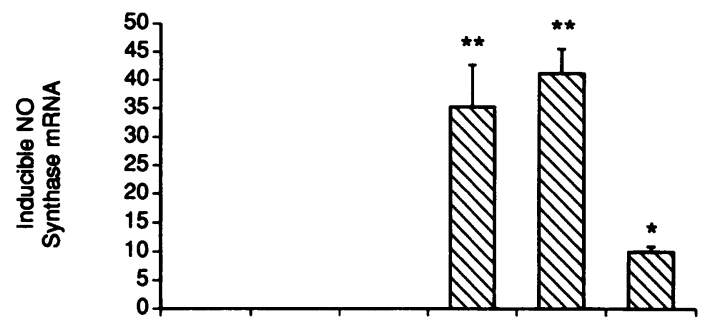

B

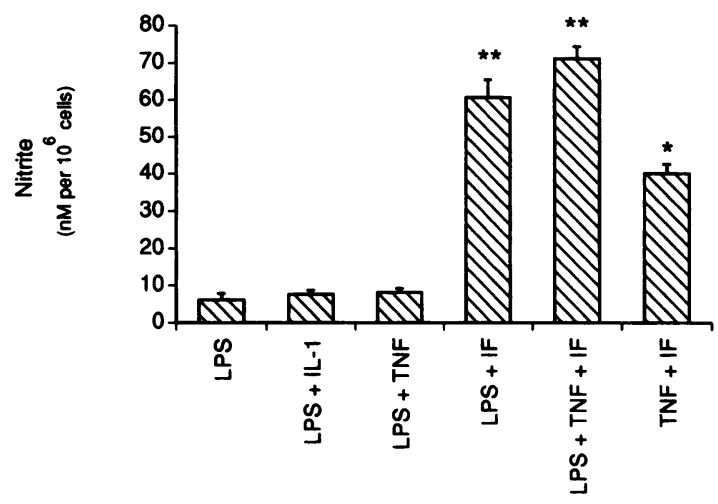

Figure 3. Effects of LPS on inducible NO synthase mRNA and nitrite. $(A)$ Lipocytes were isolated, cultured ( $4 \mathrm{~d})$, and exposed to LPS, alone or in combination with IFN- $\gamma(500 \mathrm{U} / \mathrm{ml})$, TNF- $\alpha(1,000 \mathrm{U} / \mathrm{ml})$, and IL- $\beta(50 \mathrm{pg} / \mathrm{ml})$. Total cellular RNA was isolated $24 \mathrm{~h}$ after exposure to these compounds. The integrity of RNA was documented after electrophoresis through an $0.8 \%$ formaldehyde/agarose minigel, and RNase protection assay was performed with $5 \mu \mathrm{g}$ of total RNA. Bands corresponding to inducible NO synthase mRNA were identified and quantitated by scanning densitometry, NO synthase mRNA abundance was normalized to arbitrary units by assigning the value of 10 to NO synthase mRNA abundance with IFN- $\gamma /$ TNF- $\alpha$. (B) Lipocytes, as above, were exposed to LPS, alone or with IFN- $\gamma$, TNF- $\alpha$, and IL- $1 \beta$, for $24 \mathrm{~h}$, and culture medium was removed and assayed for nitrite. Nitrite concentration is expressed relative to the number of cells in culture $(n=6$; differences between single and combined agents were highly significant, $* P<0.0001 ; * * P<0.01$ for differences between LPS/IFN- $\gamma /$ TNF$\alpha$ or IFN- $\gamma /$ LPS and IFN- $\gamma /$ TNF- $\alpha$. Differences between LPS/IFN- $\gamma$ / TNF- $\alpha$ and IFN- $\gamma /$ LPS did not achieve statistical significance). Abbreviations used: IF, interferon- $\gamma$; TNF, tumor necrosis factor- $\alpha$, IL-1, interleukin-1 $\beta$; LPS, lipopolysaccharide.

synthase mRNA was detectable at $48 \mathrm{~h}$ and was not identified in sham-operated controls after $48 \mathrm{~h}$ (Fig. 7).

Effect of TGF- $\beta 1$ on NO synthase and nitrite. Because TGF$\beta 1$ has been implicated as an important inflammatory mediator with potent effects on lipoyctes (38) and is upregulated during bile duct ligation (Bissell, D. M., personal communication), we investigated whether this agent could modulate NO synthesis in lipocytes. TGF- $\beta 1$, added simultaneously with inducers of NO synthase, reduced inducible NO synthase mRNA (62 and $58 \%$ of control for 1 and $4 \mathrm{ng} / \mathrm{ml}$, respectively; $n=4$ ) and nitrite production by $20-40 \%$ (Fig. 8 ). To exclude the possibility that these concentrations of TGF- $\beta 1$ were toxic to lipocytes, standard $\left[{ }^{14} \mathrm{C}\right]$ leucine total protein assay was performed with and without TGF- $\beta 1$. TGF- $\beta 1(4 \mathrm{ng} / \mathrm{ml})$ induced a $<10 \%$ reduction in total protein synthesis (data not shown). Further-

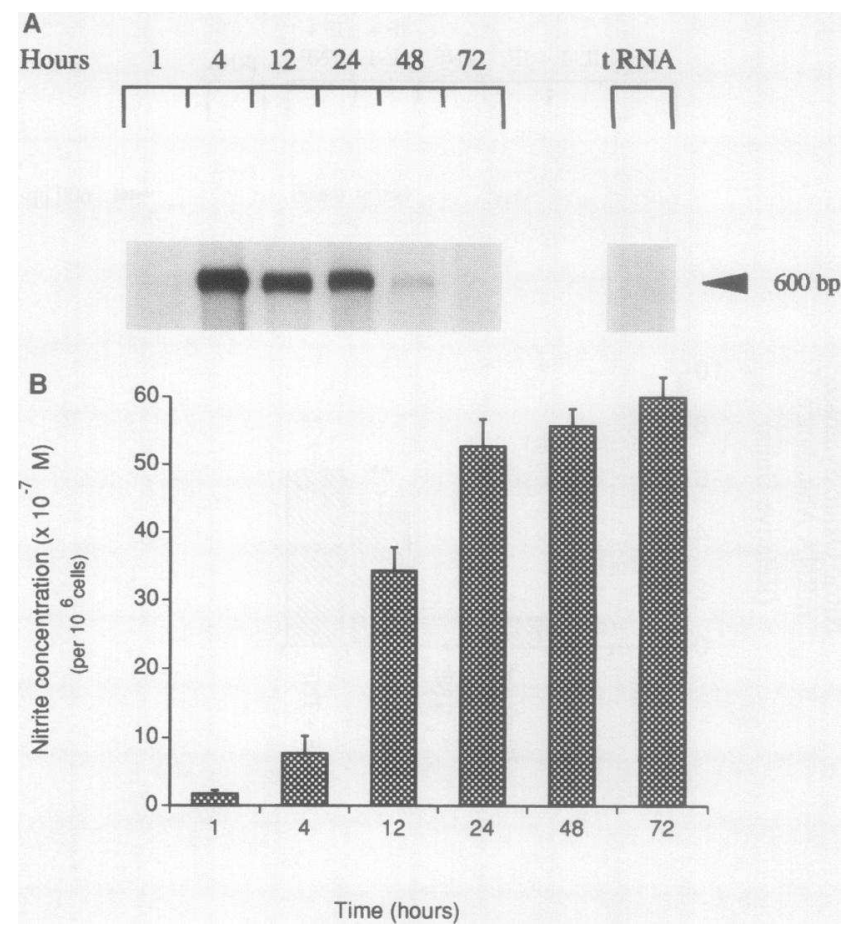

Figure 4. Time course of NO synthase induction in cultured lipocytes. After $4 \mathrm{~d}$ in primary culture, lipocytes were exposed to IFN- $\gamma$ and TNF$\alpha(500$ and $1,000 \mathrm{U} / \mathrm{ml}$, respectively). After $1,4,12,24,48$, or $72 \mathrm{~h}$, RNA was isolated and used for RNase protection assay ( $5 \mu \mathrm{g}$ of total RNA) ( $A$ ); supernatant was removed from the same cultures and assayed for nitrite as described in Methods $(B)(n=3)$.

more, toxicity of TGF- $\beta 1(4 \mathrm{ng} / \mathrm{ml})$ was excluded by the absence of an effect on uptake of propidium iodide.

Identity of "lipocyte" inducible NO synthase. Previous studies have postulated the presence of different species of inducible NO synthase (39). To clarify further the identity of the inducible NO synthase isolated from lipocytes, total RNA from

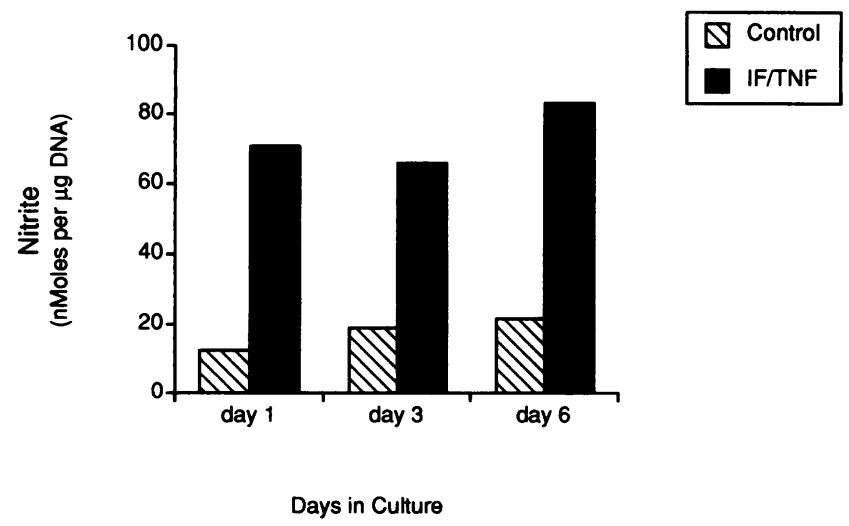

Figure 5. Nitrite production as a function of time in culture. Lipocytes were isolated and cultured as in Fig. 1. After 1, 3, and $6 \mathrm{~d}$ in primary culture, medium containing IFN- $\gamma$ and TNF- $\alpha$ (500 and $1,000 \mathrm{U} / \mathrm{ml}$, respectively) was added. $24 \mathrm{~h}$ later, medium was removed for nitrite assay, and the DNA content of the cell monolayer was determined as described in Methods. Nitrite levels were expressed relative to total cellular DNA. The data shown are representative of three independent experiments. 


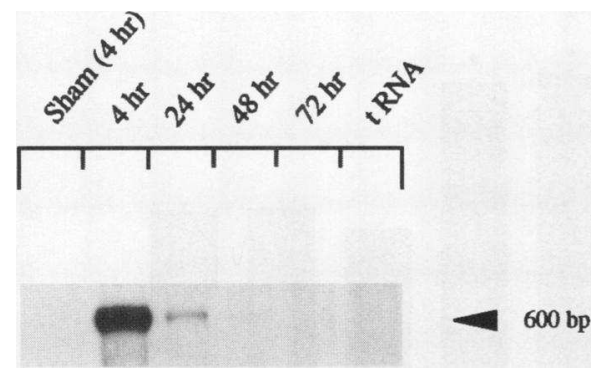

Figure 6. Stimulation of NO synthase mRNA in vivo by LPS, IFN- $\gamma$, and TNF- $\alpha$. LPS, IFN- $\gamma$, and TNF- $\alpha(10 \mu \mathrm{g}, 10,000$, and $20,000 \mathrm{U}$, respectively) were combined in PBS containing $1 \%$ BSA and injected into the intraperitoneal cavity. $4,24,48$, and $72 \mathrm{~h}$ later, cell isolations were performed, and cell isolates were immediately homogenized in guanidinium isothiocyanate as described in Methods. Sham injection consisted of the above vehicle without cytokines or LPS. RNase protection assay was performed using $10 \mu \mathrm{g}$ of total RNA as a template. The data shown are representative of three independent experiments.

control cells or those stimulated with IFN- $\gamma$ and TNF- $\alpha$ was hybridized with either radiolabeled cRNA derived from a subcloned fragment of the previously identified mouse macrophage inducible NO synthase cDNA (5) or the present inducible NO synthase cDNA. Samples were later incubated with either T2 RNase or RNase A plus RNase T1. The latter combination of RNases cleaves single incongruous base pairs, so that complementation must be complete for full-length fragments to be protected and detected.

In RNase protection assay using samples probed with the mouse macrophage inducible NO synthase cRNA followed by T2 RNase, a protected mRNA fragment of the appropriate size was detected (Fig. 9). However, after RNase A/T1 digestion, this signal was eliminated. In contrast, the band resulting from hybridization of lipocyte mRNA and the vascular smooth muscle cRNA was not affected by RNase A/T1 digestion.

Effect of NO on lipocyte contraction. We and others have previously demonstrated that lipocyte contraction can be stimulated by either serum or endothelin- 1,2 , or $3(25,40)$; the latter substances are particularly potent agonists of lipocyte contraction. When NO was induced in lipocytes by the combination of IFN- $\gamma$ and TNF- $\alpha$ or by IFN- $\gamma$ and IL- $1 \beta$, seruminduced contraction was markedly inhibited (Fig. 10). Lattice area was $45.8 \pm 1.2 \%$ compared with $84.2 \pm 1.3 \%$ for control versus IFN- $\gamma /$ TNF- $\alpha$ treated, respectively (Fig. $9 A$ ). Moreover, addition of an inhibitor of NO synthase, $\mathrm{N}^{\mathrm{G}}$-monometh-

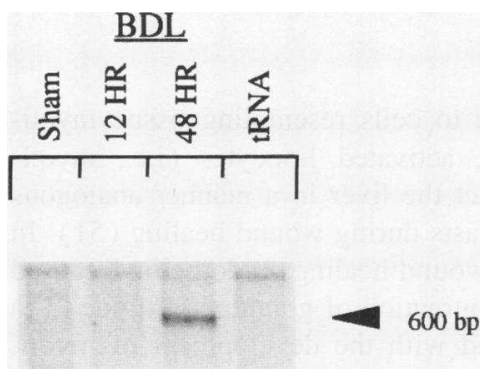

Figure 7. Upregulation of NO synthase mRNA in lipocytes after bile duct ligation. The bile duct was ligated and sectioned as described in Methods. Lipocytes were isolated after bile duct ligation at the indicated time points. Sham animals underwent laparotomy and palpation of the bile duct, which remained intact. $10 \mu \mathrm{g}$ of total cellular RNA was used for RNase protection assay. A representative (of three separate experiments) RNase protection assay is shown.

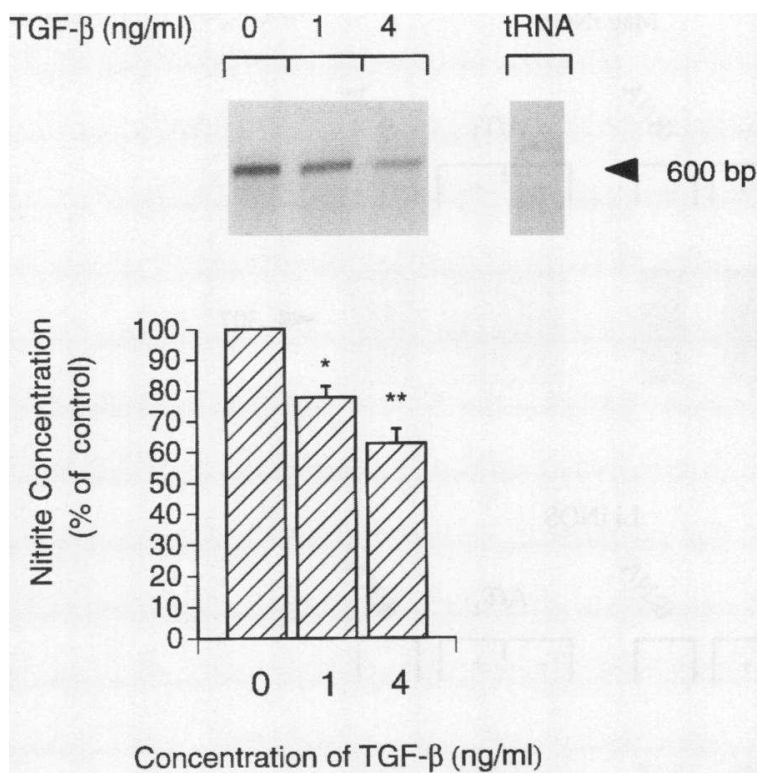

Figure 8. Lipocyte inducible NO synthase mRNA and NO are inhibited by TGF- $\beta 1$. Lipocytes were isolated and cultured as described in Methods. IFN- $\gamma$ and TNF- $\alpha$, with or without TGF- $\beta 1$ ( 1 or $4 \mathrm{ng}$ ), were added to cultures. $24 \mathrm{~h}$ later, culture supernatant was removed, and nitrite levels were measured. RNA was isolated, and RNase protection assay was performed ( $5 \mu \mathrm{g}$ of total RNA). A representative RNase protection assay $(n=4)$ is shown in the top portion of the figure. The nitrite level with IFN- $\gamma$ and TNF- $\alpha$ together was arbitrarily set at $100 \%$. ${ }^{*} P<0.05,{ }^{*} P<0.005$ for IFN- $\gamma /$ TNF- $\alpha$ versus IFN- $\gamma /$ TNF- $\alpha$ plus TGF- $\beta 1(n=6)$.

ylarginine (NMMA), returned contraction to control values. Whereas neither IL- $1 \beta$ nor TNF- $\alpha$ alone had an effect on lipocyte contraction, IFN- $\gamma$ alone had a detectable, albeit small, effect on lipocyte contraction (data not shown). The effect of NO on endothelin-1-mediated lipocyte contraction was analogous to that observed for serum-induced contraction (Fig. $9 \mathrm{~B}$ ). In the case of endothelin-1, the effect of combined IFN- $\gamma$ and IL- $1 \beta$ was the same as that of IFN- $\gamma$ and TNF- $\alpha$ (data not shown ).

The known effect of NO on relaxation of cells is via cyclic guanosine monophosphate (cGMP) signaling. To corroborate further that the effect of added cytokines on lipocyte contraction was due to NO, we examined the effect of 8-bromoguanosine $3^{\prime}: 5^{\prime}$-cyclic monophosphate (BrcGMP), a cGMP analog, and sodium nitroprusside, a NO donor, on lipocyte contractility. Both of these agents inhibited lipocyte contraction; the effect at high concentrations was striking (Table I). High concentrations of BrcGMP ( $8 \mathrm{mM})$ and sodium nitroprusside ( $3 \mathrm{mM}$ ) had no effect on lipocyte morphology, cell spreading, or ability to exclude propidium iodide.

\section{Discussion}

The cellular and molecular mechanisms by which liver blood flow is regulated in both normal and cirrhotic liver are under active investigation. Because of their anatomic orientation within the hepatic sinusoid (i.e., analogous to tissue pericytes), it has been hypothesized that lipocytes may be important in regulation of sinusoidal blood flow. For example, in normal liver, portal pressure increases after perfusion of the smooth 


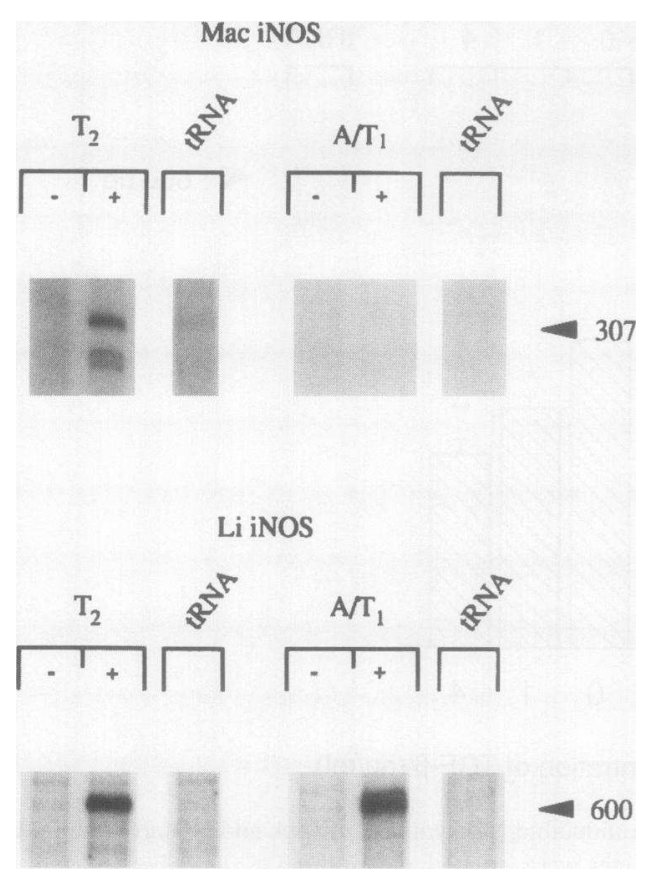

Figure 9. Identity of "lipocyte" inducible NO synthase mRNA. Lipocytes were isolated, cultured, and exposed to IFN- $\gamma$ and TNF- $\alpha$ as in Fig. 4. Control cells were cultured under standard conditions (not exposed to cytokines). RNase protection assay ( $5 \mu \mathrm{g}$ of total RNA) was performed with either radiolabeled cRNA derived from a subcloned fragment ( $307 \mathrm{bp}$ ) of the previously identified mouse macrophage inducible NO synthase cDNA (4) or cRNA from the present inducible NO synthase in the presence of T2 RNase or RNase A plus RNase T1. The RNase protection assay shown is representative of three independent experiments.

muscle contractile agonist endothelin-1 $(23,41)$ and sinusoidal diameter may decrease $(42,43)$. Although presinusoidal effects on smooth muscle cells were not excluded, these data imply a role for lipocytes. This inference is supported by data demonstrating direct effects of endothelin-1 or serum on the contraction of lipocytes cultured on silicon rubber membranes or collagen lattices $(25,40)$.

Whether NO regulates sinusoidal blood flow in normal liver via effects on lipocytes or on smooth muscle cells (pre- or postsinusoidal) is unknown at present. Although induction of NO synthase may not occur under normal physiologic conditions, its stimulation by endotoxin suggests a role in septic shock $(21,44,45)$. Alternatively, cirrhotic patients have been reported to have elevated plasma endotoxin (as well as nitrite) levels compared with controls, implying a role of NO in the hemodynamic alterations in cirrhosis (37). Finally, cytokines, including those that we have shown to stimulate NO synthase in lipocytes, are prominent in patients with inflammatory and/or chronic liver diseases (46). For example, TNF- $\alpha$, a prominent Kupffer cell product, has been identified in high levels in the plasma of patients with inflammatory liver disease $(47,48)$ and IFN- $\gamma$ may be released by macrophages after exposure to LPS (49). Thus, by induction of NO synthase, cytokines could modulate lipocyte or smooth muscle cell contractility in inflammatory or chronic liver disease.

Recent evidence has demonstrated that during liver injury, lipocytes undergo activation. This process is characterized by de novo expression of smooth muscle $\alpha$-actin and morphologic
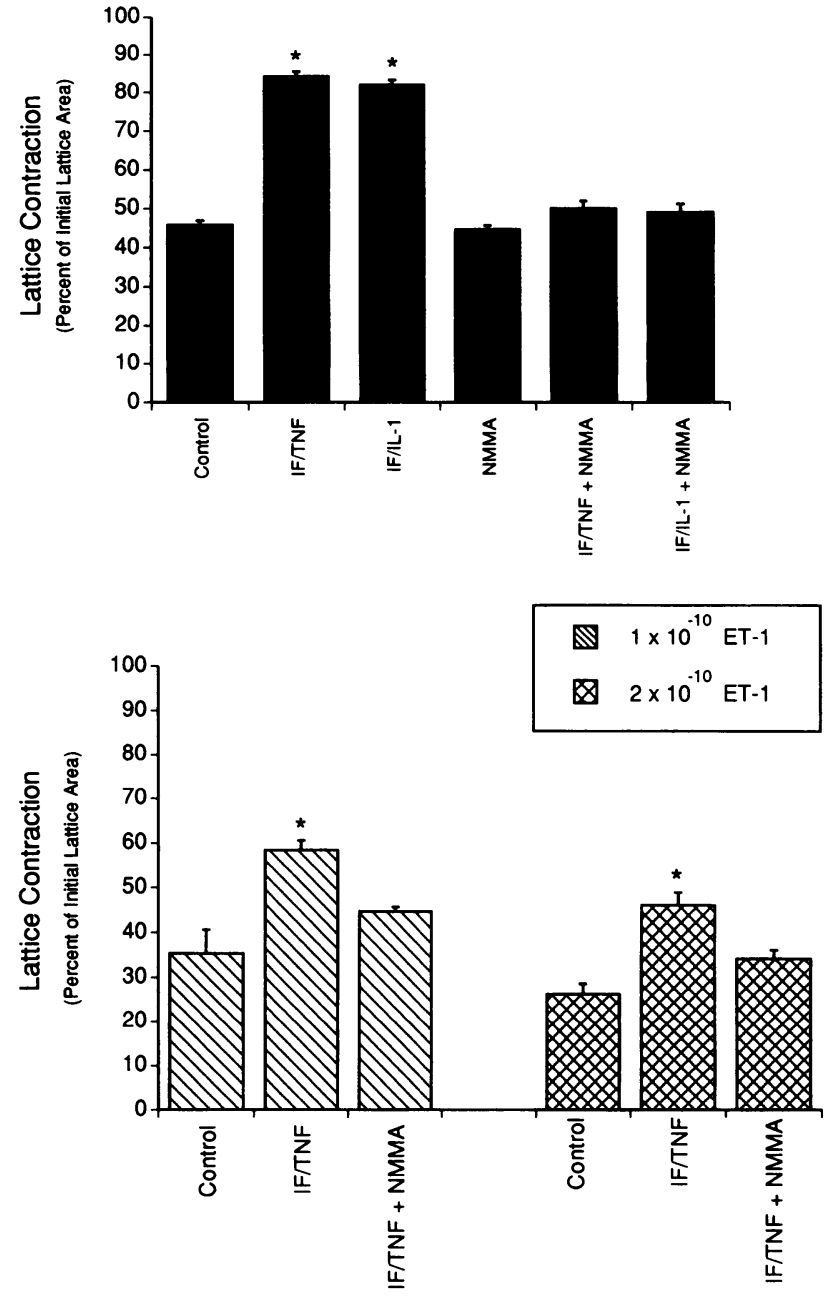

Figure 10. Effects of NO on lipocyte contraction. Lipocytes were isolated and layered on top of thick collagen lattices as described in Methods. After $5 \mathrm{~d}$ in primary culture, fresh medium with IFN- $\gamma$ ( $500 \mathrm{U} /$ $\mathrm{ml}), \mathrm{TNF}-\alpha(1,000 \mathrm{U} / \mathrm{ml}), \mathrm{IL}-1 \beta(50 \mathrm{pg} / \mathrm{ml})$, alone or in combination, was added to cultures. $4 \mathrm{~h}$ later, collagen lattices were dislodged from their plastic substrata, and lattice diameter was measured over time $(A)$. Contraction $24 \mathrm{~h}$ after lattice release is shown. In some cultures $(B)$, endothelin- $1\left(10^{-10}\right.$ or $\left.2 \times 10^{-10} \mathrm{M}\right)$, an agonist of lipocyte contraction, was added $1 \mathrm{~h}$ before lattice dislodgement. For some experiments, NMMA $(0.25 \mathrm{mM})$ was added with cytokines. Control refers to cultures without IFN- $\gamma$, TNF- $\alpha$, or IL- $1 \beta(n=4 * P<0.001$ for differences between control and IFN- $\gamma$ plus TNF- $\alpha$ or IFN- $\gamma$ plus IL- $1 \beta$; there was no statistical difference in contraction between IFN- $\gamma$ plus TNF- $\alpha$ and IFN- $\gamma$ plus IL- $1 \beta$ nor was there a statistical difference between control and any condition with NMMA). Abbreviations used: IF, interferon- $\gamma$; TNF, tumor necrosis factor- $\alpha$; IL-1, interleukin- $1 \beta$.

transformation of lipocytes to cells resembling tissue myofibroblasts (50). Moreover, activated lipocytes (i.e., myofibroblasts) appear to contract the liver in a manner analogous to that of tissue myofibroblasts during wound healing (51). In an experimental model of wound healing, endothelin- 1 caused concentration-dependent contraction of granulation tissue (52) and this response correlated with the development of myofibroblasts in the injured tissue. Thus, endothelins or other contractile agonists may have effects on myofibroblasts in many forms of wound healing, including that in the liver. In this regard, the data demonstrating upregulation of NO synthase in 
Table I. Effect of NO, Sodium Nitroprusside, and cGMP on Lipocyte Contraction

\begin{tabular}{lll}
\hline & \multicolumn{2}{c}{ Contraction (\% of initial lattice area) } \\
\cline { 2 - 3 } \multicolumn{1}{c}{ Agent(s) } & Standard medium & Endothelin-1 \\
\hline None (control) & $49.2 \pm 2.8$ & $29.3 \pm 2.3$ \\
IFN- $\gamma+$ TNF- $\alpha$ & $81.1 \pm 2.9^{*}$ & $55.1 \pm 7.9^{\ddagger}$ \\
BrcGMP & & \\
$0.5 \mathrm{mM}$ & $76.7 \pm 7.8^{\ddagger}$ & $43.6 \pm 6.2^{\ddagger}$ \\
$2.0 \mathrm{mM}$ & $83.7 \pm 7.2^{*}$ & $59.5 \pm 6.4^{*}$ \\
$8.0 \mathrm{mM}$ & $97.0 \pm 0.0^{*}$ & $75.4 \pm 4.0^{*}$ \\
Sodium nitroprusside & & \\
$0.5 \mathrm{mM}$ & $84.2 \pm 1.8^{*}$ & $66.3 \pm 3.7^{*}$ \\
$3 \mathrm{mM}$ & $95.9 \pm 1.1^{*}$ & $76.4 \pm 1.0^{*}$ \\
& & \\
\hline
\end{tabular}

Lipocytes were isolated and layered on top of collagen lattices as described in Methods. After $5 \mathrm{~d}$ in culture, medium was changed and the shown agents were added. $4 \mathrm{~h}$ later, collagen lattices were dislodged from their culture vessel and the lattice contraction was measured. The data shown represent contraction $24 \mathrm{~h}$ after release. Standard medium contains $20 \%$ serum, as described in Methods. Endothelin-1 is $0.1 \mathrm{nM}$, IFN- $\gamma$ is $500 \mathrm{U} / \mathrm{ml}$, and TNF- $\alpha$ is $1,000 \mathrm{U} / \mathrm{ml}$. Contraction assay for each condition was performed in duplicate, and the average was used as an individual experimental number. $n=3,{ }^{\ddagger} P<0.05,{ }^{*} P<0.005$ for control (either standard medium or endothelin-1) compared with added agents.

a model of liver injury (bile duct ligation) raise the possibility that in vivo, NO may serve as a counter-regulator of "myofibroblast" contraction. Although the mechanism by which NO synthase is stimulated in bile duct ligation is unknown, IFN- $\gamma$ and TNF- $\alpha$ are among the cytokines that may be upregulated. We speculate that the contractile status of myofibroblasts in wound healing could ultimately be determined by the balance between contractile agonists such as endothelin-1 and antagonists such as NO. Further investigation will be necessary to elucidate the relation between expression of agents such as endothelin-1, release of cytokines, and induction of NO synthase.

In injured tissue, factors that modulate NO production (and/ or endothelin) and thereby affect the contractility of lipocytes or other contractile cells are undoubtedly complex. For example, we demonstrated that inducible NO synthase mRNA and NO in lipocytes can be inhibited by TGF- $\beta 1$. Thus, the resultant state of contractility in vivo (i.e., net contraction or relaxation) is likely to be ultimately determined by the complex interplay of soluble factors such as IFN- $\gamma$, TNF- $\alpha$, and LPS, as well as TGF- $\beta 1$. Although soluble factors have so far been emphasized, signals from extracellular matrix interactions, expression of specific cognate receptors, or other as yet unknown factors may also play important roles in regulation of NO synthase and NO. Such a system provides for fine control of NO production and key processes such as wound contraction (and capillary flow).

Endothelial cell-derived NO, which is largely constitutive, presumably exerts its effects in a paracrine fashion on smooth muscle cells. Although recent data demonstrate that NO may diffuse through distances representing several cell layers (27), its potency by this route, relative to an autocrine one, is open to question. Since we used pure cultures of lipocytes for contraction studies, the observed effects of NO on lipocyte contractility were purely autocrine (or "intracrine"'). The concept that autocrine NO is important may apply generally to the regulation of smooth muscle contraction, in which inducible NO synthase activity has been demonstrated $(8,15,53)$. Additionally, in wound healing, myofibrobasts are thought to be responsible for the physical contraction of the scar (54) and have been shown to respond to contractile agonists (55). In wound healing, except in circumstances in which neovascularization with endothelial cell proliferation is prominent, NO derived from constitutive endothelial sources is unlikely to be present. Our study suggests that NO generated by myofibroblasts (i.e., such as activated lipocytes) may serve as an important autocrine relaxing factor.

A number of unique inducible NO synthases within a particular species have been postulated (39). Including the one reported here, four cDNAs coding for inducible NO synthases have been identified in the liver $(17,18,39)$. Inducible NO synthase has been cloned from human hepatocytes, rat hepatocytes, and a rat liver library $(17,18,39)$. Adachi et al. (39) reported 93.1 and $93.7 \%$ nucleotide homology between their cDNA and cDNAs cloned from rat vascular smooth muscle cells (15) and rat hepatocytes (18), respectively. However, comparison of the full-length sequences from GenBank with the GAP program (Wisconsin Genetics Computer Group), indicated 99.6 and $99.5 \%$ homology between the vascular smooth muscle clone and the rat liver and rat hepatocyte clones, respectively. Additionally, our cDNA is identical to the rat vascular smooth muscle sequence. These data suggest that all of the rat cDNAs are identical. To support further the concept of a conserved protein within a species, we were able to demonstrate "vascular smooth muscle" inducible NO synthase mRNA in rat liver endothelial cells, hepatocytes, and Kupffer cells using the highly stringent RNase protection assay with RNase A/T1 (data not shown). This result indicates that apparently all major liver cell types express at least this isoform of inducible NO synthase.

\section{Acknowledgments}

Portions of this work were presented in abstract form at the 1994 meeting of the American Federation for Clinical Research (April 29-May 2, Baltimore, MD). This work was supported by the American Liver Foundation, the Glaxo Institute for Digestive Health, and the National Institutes of Health (grants DK-02124, DK-26743, and DK-31198). We thank Dr. J. M. Cunningham for providing cDNA for mouse macrophage inducible NO synthase, Dr. J. J. Maher for assistance with RNase A/T1 preparation, and Dr. D. M. Bissell for helpful discussions and review of the manuscript.

\section{References}

1. Palmer, R. M. J., D. S. Aston, and S. Moncada. 1988. Vascular endothelial cells synthesize nitric oxide from L-arginine. Nature (Lond.). 333:664-666.

2. Sakuma, I., D. J. Stuehr, S. S. Gross, C. Nathan, and R. Levi. 1988. Identification of arginine as a precursor of endothelium-derived relaxing factor. Proc. Natl. Acad. Sci. USA. 85:8664-8667.

3. Xie, Q., H. J. Cho, J. Calaycay, R. A. Mumford, K. M. Swiderek, T. D. Lee, A. Ding, T. Troso, and C. Nathan. 1992. Cloning and characterization of inducible nitric oxide synthase from mouse macrophages. Science (Wash. DC). 256:225-228.

4. Lowenstein, C. J., C. S. Glatt, D. S. Bredt, and S. H. Snyder. 1992. Cloned and expressed macrophage nitric oxide synthase contrasts with the brain enzyme. Proc. Natl. Acad. Sci. USA. 89:6711-6715.

5. Lyons, C. R., G. J. Orloff, and J. M. Cunningham. 1992. Molecular cloning and functional expression of an inducible nitric oxide synthase from a murine macrophage cell line. J. Biol. Chem. 267:6370-6374.

6. Billiar, T. R., R. D. Curran, D. J. Stuehr, M. A. West, B. G. Bentz, and 
R. L. Simmons. 1989. An L-arginine-dependent mechanism mediates Kupffer cell inhibition of hepatocyte protein synthesis in vitro. J. Exp. Med. 169:1467-1472.

7. Bredt, D. S., P. M. Hwang, and S. H. Snyder. 1990. Localization of nitric oxide synthase indicating a neural role for nitric oxide. Nature (Lond.). 347:768770.

8. Nunokawa, Y., and S. Tanaka. 1992. Interferon-gamma inhibits proliferation of rat vascular smooth muscle cells by nitric oxide generation. Biochem. Biophys. Res. Commun. 188:409-415.

9. Balligand, J. L., D. Ungureanu, R. A. Kelly, L. Kobzik, D. Pimental, T. Michel, and T. W. Smith. 1993. Abnormal contractile function due to induction of nitric oxide synthesis in rat cardiac myocytes follows exposure to activated macrophage-conditioned medium. J. Clin. Invest. 91:2314-2319.

10. Curran, R. D., T. R. Billiar, D. J. Stuehr, K. Hofmann, and R. L. Simmons. 1989. Hepatocytes produce nitrogen oxides from L-arginine in response to inflammatory products of Kupffer cells. J. Exp. Med. 170:1769-1774.

11. Lamas, S., P. A. Marsden, G. K. Li, P. Tempst, and T. Michel. 1992. Endothelial nitric oxide synthase: molecular cloning and characterization of a distinct constitutive enzyme isoform. Proc. Natl. Acad. Sci. USA. 89:6348-6352.

12. Janssens, S. P., A. Shimouchi, T. Quertermous, D. B. Bloch, and K. D. Bloch. 1992. Cloning and expression of a cDNA encoding human endotheliumderived relaxing factor/nitric oxide synthase. J. Biol. Chem. 267:14519-14522.

13. Sessa, W. C., J. K. Harrison, C. M. Barber, D. Zeng, M. E. Durieux, D. D. D’Angelo, K. R. Lynch, and M. J. Peach. 1992. Molecular cloning and expression of a cDNA encoding endothelial cell nitric oxide synthase. J. Biol. Chem. 267:15274-15276.

14. Bredt, D. S., P. M. Hwang, C. E. Glatt. C. Lowenstein, R. R. Reed, and S. H. Snyder. 1991. Cloned and expressed nitric oxide synthase structurally resembles cytochrome P-450 reductase. Nature (Lond.). 351:714-718.

15. Nunokawa, Y., N. Ishida, and S. Tanaka. 1993. Cloning of inducible nitric oxide synthase in rat vascular smooth muscle cells. Biochem. Biophys. Res. Commun. 191:89-94.

16. Charles, I. G., R. M. J. Palmer, M. S. Hickery, M. T. Bayliss, A. P. Chubb, V. S. Hall, D. W. Moss, and S. Moncada. 1993. Cloning, characterization, and expression of a cDNA encoding an inducible nitric oxide synthase from the human chondrocyte. Proc. Natl. Acad. Sci. USA. 90:11419-11423.

17. Geller, D. A., C. J. Lowenstein, R. A. Shapiro, A. K. Nussler, M. Di Silvio, S. C. Wang, D. K. Nakayama, R. L. Simmons, S. H. Snyder, and T. R. Billiar. 1993. Molecular cloning and expression of inducible nitric oxide synthase from human hepatocytes. Proc. Natl. Acad. Sci. USA. 90:3491-3495.

18. Wood, E. R., H. Berger, P. A. Sherman, and E. G. Lapetina. 1993. Hepatocytes and macrophages express an identical cytokine inducible nitric oxide synthase gene. Biochem. Biophys. Res. Commun. 191:767-774.

19. Nathan, C. 1992. Nitric oxide as a secretory product of mammalian cells. FASEB (Fed. Am. Soc. Exp. Biol.) J. 6:3051-3064.

20. Lowenstein, C. J., and S. H. Snyder. 1992. Nitric oxide, a novel biologic messenger. Cell. 70:705-707.

21. Spitzer, J. A. 1994. Cytokine stimulation of nitric oxide formation and differential regulation in hepatocytes and nonparenchymal cells of endotoxemic rats. Hepatology. 19:217-228.

22. Knowles, R. G., M. Merrett, M. Salter, and S. Moncada. 1990. Differential induction of brain, lung and liver nitric oxide synthase by endotoxin in the rat. Biochem. J. 270:833-836.

23. Tran-Thi, T., N. Kawada, and K. Decker. 1993. Regulation of endothelin1 action on the perfused rat liver. FEBS (Fed. Eur. Biochem. Soc.) Lett. 318:353357.

24. Housset, C., D. C. Rockey, and D. M. Bissell. 1993. Endothelin receptors in rat liver: lipocytes as a contractile target for endothelin-1. Proc. Natl. Acad. Sci. USA. 90:9266-9270.

25. Rockey, D. C., C. Housset, and S. L. Friedman. 1993. Activation-dependent contractility of rat hepatic lipocytes in culture and in vivo. J. Clin. Invest. 92:1795-1804.

26. Feder, L. S., and D. L. Laskin. 1994. Regulation of hepatic endothelial and macrophage proliferation and nitric oxide production by GM-CSF, M-CSF, and IL-1 $\beta$ following acute endotoxemia. J. Leukocyte Biol. 55:507-513.

27. Kharitonov, V. G., A. R. Sundquist, and V. J. Sharma. 1994. Kinetics of nitric oxide autoxidation in aqueous solution. J. Biol. Chem. 269:5881-5883.

28. Friedman, S. L., and F. J. Roll. 1987. Isolation and culture of hepatic lipocytes, Kupffer cells, and sinusoidal endothelial cells by density gradient centrifugation with Stractan. Anal. Biochem. 161:1233-1247.

29. Gressner, A. M., and R. Haarmann. 1987. The synthesis of proteoglycans in fat storing cells of rat liver. Hepatology. 7:680-687.
30. Irving, M. G., F. J. Roll, S. Huang, and D. M. Bissell. 1984. Characterization and culture of sinusoidal endothelium from normal rat liver: lipoprotein uptake and collagen phenotype. Gastroenterology. 87:1233-1247.

31. Chomczynski, P., and N. Sacchi. 1987. Single-step method of RNA isolation by acid guanidinium thiocyanate-phenol-chloroform extraction. Anal. Biochem. 162:156-159.

32. Melton, D. A., P. A. Krieg, M. R. Rebagaliati, T. Maniatis, K. Zinn, and M. R. Green. 1984. Efficient in vitro synthesis of biologically active RNA and RNA hybridization probes from plasmids containing a bacteriophage SP6 promoter. Nucleic Acids Res. 12:7035-7056.

33. Ausubel, F. M., R. Brent, R. E. Kingston, D. D. Moore, J. G. Seidman, J. A. Smith, and K. Struhl. 1988. Current Protocols in Molecular Biology. John Wiley \& Sons, Inc., New York.

34. Green, L. C.. D. A. Wagner, J. Glogowski, P. L. Skipper, J. S. Wishnok, and S. R. Tannenbaum. 1982. Analysis of nitrate, nitrite, and $\left[{ }^{15} \mathrm{~N}\right]$ nitrate in biological fluids. Anal. Biochem. 126:131-138

35. Labarca, C., and K. Paigen. 1980. A simple, rapid, and sensitive DNA assay procedure. Anal. Biochem. 102:344-352.

36. Kountouras, J., B. H. Billing, and P. J. Scheuer. 1984. Prolonged bile duct obstruction: a new experimental model for cirrhosis in the rat. Br. J. Exp. Pathol. 65:305-311.

37. Guarner, C., G. Soriano, A. Tomas, O. Bulbena, M. T. Novella, J. Balanzo, F. Vilardell, M. Mourelle, and S. Moncada. 1993. Increased serum nitrite and nitrate levels in patients with cirrhosis: relationship to endotoxemia. Hepatology. 18:1139-1143.

38. Davis, B. H.. R. T. Kramer, and N. O. Davidson. 1990. Retinoic acid modulates rat Ito cell proliferation, collagen, and transforming growth factor $\beta$ production. J. Clin. Invest. 86:2062-2070.

39. Adachi, H., S. Iida, S. Oguchi, H. Ohshima, H. Suzuki, K. Nagasaki, H. Kawasaki, T. Sugimura, and H. Esumi. 1993. Molecular cloning of a cDNA encoding an inducible calmodulin-dependent nitric-oxide synthase from rat liver and its expression in COS 1 cells. Eur. J. Biochem. 217:37-43.

40. Kawada, N., H. Klein, and K. Decker. 1992. Eicosanoid-mediated contractility of hepatic stellate cells. Biochem. J. 285:367-371.

41. Gandi, C. R., K. Stephenson, and M. S. Olson. 1990. Endothelin, a potent peptide agonist in the liver. J. Biol. Chem. 265:17432-17435.

42. Okumura, S., T. Yoshiyuki, S. Kawano, K. Nagano, E. Masuda, M. Goto, S. Tsuji, T. Michida, S. Song, T. Kashiwagi, H. Fusamoto, T. Kamada, and N. Sato. 1994. Vasoactive effect of endothelin-1 in rat liver in vivo. Hepatology. 19:155-161.

43. Zhang, J. X., W. Pegoli, and M. G. Clemens. 1994. Endothlein-1 induces direct constriction of hepatic sinusoids. Am. J. Physiol. 266:G624-G632

44. Moncada, S., and A. Higgs. 1993. The L-arginine-nitric oxide pathway. N. Engl. J. Med. 329:2002-2012.

45. Nathan, C., and Q. Xie. 1994. Regulation of biosynthesis of nitric oxide. J. Biol. Chem. 269:13725-13728.

46. Andus, T., J. Bauer, and W. Gerok. 1991. Effects of cytokines on the liver. Hepatology. 13:364-375.

47. Bird, G. L. A., N. Sheron, J. Goka, G. J. Alexander, and R. S. Williams. 1990. Increased plasma tumor necrosis factor in severe alcoholic heaptitis. Ann. Intern. Med 112:917-920.

48. Decker, K. 1990. Biologically active products of stimulated liver macrophages (Kupffer cells). Eur. J. Biochem. 192:245-261.

49. Fultz, M. J., S. A. Barber, C. W. Dieffenbach, and S. N. Vogel. 1993. Induction of IFN- $\gamma$ by lipopolysaccharide. Int. Immunol. 5:1383-1392.

50. Rockey, D. C., J. K. Boyles, G. Gabbiani, and S. L. Friedman. 1992. Rat hepatic lipocytes express smooth muscle actin upon activation in vivo and in culture. J. Submicrosc. Cytol. Pathol. 24:193-203.

51. Irle, C., O. Kocher, and G. Gabbiani. 1980. Contractility of myofibroblasts during experimental liver cirrhosis. J. Submicrosc. Cytol. 12:209-217.

52. Appleton, I., A. Tomlinson. C. L. Chander, and D. A. Willoughby. 1993. Effect of endothelin-1 on croton oil-induced granulation tissue in the rat. Lab. Invest 67:703-710.

53. Nakayama, D. K., D. A. Geller, C. J. Lowenstein, P. Davies, B. R. Pitt, R. L. Simmons, and T. R. Billiar. 1992. Cytokines and lipopolysaccharide induce nitric oxide synthase in cultured rat pulmonary artery smooth muscle. Am. J. Respir. Cell Mol. Biol. 7:471-476. 532.

54. Gabbiani, G. 1992. The biology of the myofibroblast. Kidney Int. 41:530-

55. Gabbiani, G., B. J. Hirschel, G. B. Ryan, P. R. Statkov, and G. Majno. 1972. Granulation tissue as a contractile organ: study of structure and function. J. Exp. Med. 135:719-734. 